\title{
Synthetic and coal-water fuels improving is the instrument of industrial region sustainability increasing
}

\author{
Ivan Dobrovolsky ${ }^{1}$ and Dmitry Sorokin ${ }^{2, *}$ \\ ${ }^{1}$ Retiree, 30, Chicherina str., 454003, Chelyabinsk, Russia \\ ${ }^{2}$ Chelyabinsk State University, 129, Bratiev Kashirinykh str., 454001 Chelyabinsk, Russia
}

\begin{abstract}
New methods of processing bituminous and brown coal in synthetic and coal-water fuel production are now gaining relevance. On the one hand, this is dictated by the pragmatic need to reduce the dependence of industrial energy consumers on the prices and quality of hydrocarbon raw materials, especially in the context of the constant exacerbation of market restrictions associated with the pandemic and sanctions, on the other hand, there is an urgent need for environmentally friendly methods of using synthetic and coal-water fuels. The article discusses the currently used technologies for the production of synthetic and coal-water fuels. The authors identify its main disadvantages and limitations and propose a schematic diagram of a technological line for coal-water fuel production with a linear layout. It allows obtaining fuel with good fluidity and higher stability, high-calorie content, and low ash content with less energy consumption.
\end{abstract}

\section{Introduction}

The need to develop alternative methods of producing energy sources to oil production arose quite a long time ago, back on the verge of 1970-80, when the global energy crisis became permanent, which was explained by the end of the era of cheap oil. Then various options for obtaining "clean" energy in solar, geothermal, wind energy, and sea tides were considered. However, to date, due to the low efficiency, high cost and, paradoxically, energy consumption, the processes of manufacturing generating equipment, as well as due to the disinterest of industrial energy consumers in financing the process of switching to other types of fuel and energy sources, the primary alternative energy source for oil production, according to experts, coal will remain [1]. A powerful argument in its favor is the presence of developed infrastructure for its production, transportation, and processing, the availability of a resource base with a convenient geographical location, as well as a formed economic niche that has already won its sales sector from oil production and refining [2].

As a result, in world practice, brown coal has long been processed using new efficient technologies, including synthetic and water-coal fuel production. Over the years, the

\footnotetext{
*Corresponding author: r90r@mail.ru
} 
technology has come a long way from the first synthetic fuel (gasoline) obtained from coal by the German chemist F. Bergius in 1911 to the use of coal-water suspensions for the development and implementation, which in different years worked more than 100 scientific organizations, manufacturing firms and corporations in the USA, Sweden, Great Britain, China, Japan, Canada, Italy and other countries engaged in the study and introduction of coal-water fuel [3]. The reasons for the introduction of coal-water fuel were similar - the absence of their oil deposits or the need to overcome the embargo on the supply of petroleum products, but the resulting efficiency led to the large-scale introduction of hightech methods for the synthesis of motor fuel even in the United States. Eight projects at various stages of implementation are underway in China, all of which are intended to replace traditional fuels completely. In general, in Nigeria, Qatar, Malaysia, and the United States, about 50 facilities with a total capacity of more than 300 million tons of fuel per year are at the design and construction stage [4]. Japan, India [5], Poland, Indonesia, Pakistan joined the problem. The total volume of officially announced investments in this area exceeded $\$ 15$ billion, and the production of synthetic fuel reached 20 million tons per year.

Currently, coal-water fuel can be used at almost any heat and power facilities. However, the suspension's high water content requires at least $40 \%$ of the energy obtained during fuel combustion for its evaporation. The process of grinding coal to obtain the suspension requires even higher costs: to grind 1 ton of coal, it is necessary to spend $15-20 \mathrm{~kW}$ of electricity. Besides, there is high wear and tear of equipment when grinding liquid mixtures, and therefore, there are increased costs for its depreciation. Nevertheless, despite such shortcomings, the issue of using coal-water fuel in world practice does not lose its relevance.

In scientific practice, increasing the efficiency of using fossil hydrocarbons in the electric power industry is being actively discussed. In particular, in order to reduce the energy dependence of the Republic of Kyrgyzstan on gas and oil fuels, the prospects for integrated development and environmental problems of processing brown coal in the Kavak basin using underground gasification of coal, production of water-coal fuel, and lowtemperature pyrolysis are considered, which would make it possible to obtain such commercial products from coal as water-coal fuel, power gas and synthesis gas, as well as synthetic liquid fuel [6]. To assess the suitability of coal for destructive treatment and increase the efficiency of the process, the dependences of the coal's reactivity characteristics on petrographic composition, the coalification stage, the oxidation-reduction degree, and the concentration and composition of the mineral components are determined [7].

To overcome the shortcomings and limitations of the production of coal-water fuel identified by time, fuel production issues from alternative products are actively developed and discussed. In particular, in the Asian scientific segment, projects for the gasification of production facilities based on synthetic gas production from the woodworking industry's waste are supported. A feature and advantage are that it is not only one of the potential types of bioenergy, which has not yet been studied and used in total, but that most of the resources for woodworking are purchased, and efficient processing of residues significantly reduces the cost for this industry [8 ]. The direct conversion of carbon dioxide into liquid fuel and synthetic natural gas using renewable energy sources is considered, which can also be considered a particular trend $[1,9]$.

The research of European scientists is mainly associated with expanding the possibilities of processing waste localized on the production territory to increase its efficiency and solve several accumulated environmental problems: production of alternative fuels from waste [10], thermal processing of biomass into high-calorie solid composite fuel [11]). The complexity of the alternative resources processing, the lack of solutions in 
reducing the energy consumption, and the high cost of infrastructure components for new alternative energy generating industry lead to coal is still the only alternative to the oil and gas industry in the production in industrial volumes, and therefore overcoming shortcomings, and limitations in this direction seem to be more economically justified.

\section{Materials and methods}

\subsection{Coal-water fuel production technology}

The process of producing coal-water fuel consists of three main stages:

1. Preliminary crushing of coal to a fraction of $10-12 \mathrm{~mm}$.

2. Wet grinding of coal to a fraction of $<100-150$ microns

3. Homogenization of crushed coal.

At the first stage, coal crumbs with a fraction of 10-12 mm are obtained, crushing of which is carried out on standard crushers (hammer, jaw, etc.) to the final fraction (less than 100-150 microns) in the presence of water, which is the most energy-consuming. This method is not new, but no radical alternatives have been developed to replace it [12].

For the preparation of the final coal-water fuel, the classification of the suspension leaving the vibrating mills with the release of particles of a given size is used, at the same time, homogenization is carried out, which makes it possible to eliminate the uneven distribution of coal particles inside the suspension.

\subsection{The use of cavitation for the preparation of coal-water fuel}

Since the most common equipment for wet grinding is vibrating mills filled with balls and rods, it was decided to use cavitation devices for grinding, making it possible to exclude the coal-water suspension homogenization. However, the low strength of the grinding elements of the cavitators did not allow their use for homogenization on an industrial scale, which led to the fact that these devices were used only for preliminary water treatment. In this case, the cavitation effect led to an increase in the water's $\mathrm{pH}$, and it acquired the properties of a surfactant.

\subsection{Features of combustion of water-coal fuel}

The combustion of water-coal fuel has been tested on more than a dozen types of steam and hot water boilers. In most cases, flare or vortex combustion of fuel is used, depending on the boilers' brands and the specific situation, by replacing the used nozzles with wearresistant ones.

The changes made allow vortex combustion, in which combustion and ignition are stabilized due to the supply of hot combustion products to the center of the torch, which makes it possible to increase the boiler efficiency when operating on fuel oil. In addition to flare (including vortex) combustion, there is considerable experience in using single-stage combustion of CWF in a fluidized bed, which is effective for low-power boilers and makes it possible to reduce the dependence of the efficiency of CWF combustion on the quality of the original coal.

The use of two-stage combustion of coal-water fuel makes it possible to simplify switching from fuel oil and gas to coal-water fuel during the modernization of the boiler and significantly simplify the boiler control by using a simple automation system. The specific combustion method depends on the situation: new construction or modernization and the feedstock's composition. 
It should be noted that the combustion of coal occurs before the evaporation of water that is part of the CWF. At a temperature of about $1000^{\circ} \mathrm{C}$, the combustion of coal-water fuel occurs, water decomposes into $\mathrm{H}+$ and $\mathrm{OH}$ ions, an oxidizing agent in the CWF combustion reaction. Besides, the coal particles activation by steam leads to an intensification of combustion and a decrease in the ignition temperature of coal, and the combustion of CWF droplets occurs with a small, 5-7\% excess of air, which is similar to the combustion of fuel oil.

\subsection{Methods of combustion of coal-water fuel}

Coal water fuel is a liquid fuel (liquid coal) and slightly higher viscosity than the fuel oil's viscosity: approximately $800-1000 \mathrm{mPas}$ compared to $400-440 \mathrm{mPas}$ (up to $44 \mathrm{~mm} 2$ / $\mathrm{s}$ ) for fuel oil. Accordingly, supplying coal-water fuel to the boiler furnace is very close to supplying gas and fuel oil methods. The differences are in abrasive particles in coal-water fuels and the final size of coal particles. Currently, the following combustion methods can be distinguished: classic flare combustion with the supply of water-coal fuel through burners (centrifugal, pre-chamber, combined), fluidized bed combustion, combustion with CWF gasification, combined combustion with other types of fuel (coal, gas, fuel oil).

Flare combustion is carried out according to the classical scheme: fuel is supplied under pressure through a spray burner, similar to fuel oil. An intermediate stage of gasification of a part of coal-water fuel is possible to ensure stable combustion. Completely independent combustion of coal-water fuel, which has only one energy source (coal), allows you to reduce the cost of maintaining the fuel economy. Besides, flare combustion avoids the abrasion of burners by coal particles.

Fluidized bed combustion of coal-water fuel involves spraying coal-water fuel over a preheated (up to about $900^{\circ} \mathrm{C}$ ) layer of inert material (usually sand). The heated sand ignites the coal-water fuel, and the combustion products are directed through the gas ducts. When using CWF combustion, it is necessary to mount a pipe system around the boiler to heat the heat carrier. To reduce the size of the furnace, it can be made of materials with high energy intensity. Unfortunately, the limiting factor of the fluidized bed method is the ingress of the coal's mineral part (ash) directly into the inert material, making it challenging to utilize it. Besides, it is necessary to ensure a constantly stable supply of sand to the fluidized bed to ensure the boiler's stable operating modes. The method's positive characteristics are low sensitivity to the granular composition of the CWF and low requirements for the spray nozzle.

Co-combustion of coal-water fuel with other fuel types is the most acceptable method when using CWF at already existing facilities (i.e., during modernization) is co-combustion of water-coal fuel with already used types of fuel (gas, fuel oil, coal). In this case, coalwater fuel is supplied to the boiler through one or more burners. Using a gas-oil boiler, the second fuel (gas or fuel oil, coal dust) is fed through another burner or other burners, maintaining the specified ratio. On coal-fired boilers with layered combustion, coal is fed to the grate furnace, and VUT is fed through one or several burners located above the grate furnace.

Such combustion advantages include minimal costs for modernizing the boiler while maintaining stable combustion of coal-water fuel. The use of a second fuel (gas, fuel oil, coal), which acts as a "backlight", reduces the water-coal fuel burner's requirements. The share of coal-water fuel is more than $50 \%$, which reduces fuel costs when replacing fuel oil and outside the Russian Federation and gas. The disadvantages of the combined method include the maintenance of two fuel farms: fuel oil and coal-water or gas and coal-water, which is not beneficial for boiler owners, given the short shelf life of coal-water fuel. 


\subsection{Artificial coal-water fuel production technology}

The main disadvantages of the technology for producing synthetic coal-water fuel are high metal and energy costs. So, for example, energy consumption for traditional technologies of the enterprise for the production of water-coal fuel company Yanri CWM Ltd (China), $248.18 \mathrm{kWh} / \mathrm{t}$ of products; OPU "Belovo - Novosibirsk", Russia - $192 \mathrm{kWh} / \mathrm{t}$ of products; coal mining research center (Japan) - $86.12 \mathrm{kWh} / \mathrm{t}$ of products. The main reason for the high specific energy consumption is the low (less than 1\%) energy efficiency of wet ball mills. Rod mills for wet grinding have slightly better energy performance, but the specific energy consumption is also high when using them. One of the disadvantages of this technology is the low stability (stability) of CWF, which does not exceed 1-2 months. The schematic process flow diagram of CWF production is shown in Fig. 1.

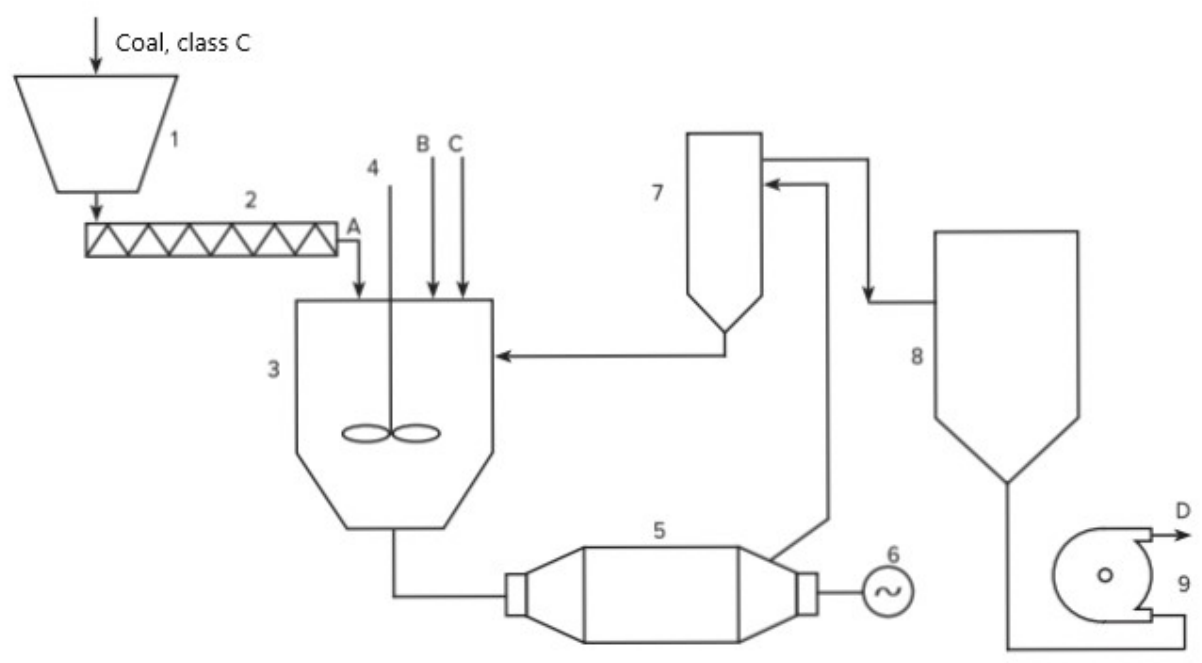

Fig. 1. Basic technology of CWF production: 1 - coal bunker; 2 - screw feeder; 3 - mixer; 4 - stirrer; 5 - ball mill for wet grinding; 6 - electric drive; 7 - hydrocyclone; 8 - intermediate tank;

9 - consumable peristaltic pump. A - raw coal; B - water; C - additives; D - ready-made CWF.

\section{Results}

In connection with the identified communication limitations, in order to improve the quality of coal-water fuel and the productivity of the system, it is necessary to increase the activity (reactivity) of both solid and liquid components by using other methods of processing mineral raw materials in devices based on new physical processes for this industry. This would make it possible to obtain fuel with increased reactivity, suitable for storage without destroying the physicochemical system for more than a year - a synthetic composite liquid fuel. The technological scheme for the production of such fuel is shown in Fig. 2. Coal A from hopper 1 is fed by feeder-metering device 2 to the primary crusher 3 . The coal initially crushed to a fraction of $2 \mathrm{~mm}$ enters the ultrafine grinding disperser 4, in which it is ground to a powder with an average particle size of $30 \mu \mathrm{m}$. In mixer 5, coal powder is actively mixed with water $\mathrm{B}$ and technological additives $\mathrm{C}$, which ameliorate the properties of IKZhT. The mixture from the mixer enters the cavitator 6 , in which the fuel composition is refined. In this case, a significant ultrafine fraction (5-10 microns) of coal is formed, and changes in the liquid phase's composition also occur. If necessary, depending on the original coal grade, the fuel processing can be carried out in a cyclic mode using buffer tank 
7 , because the productivity of the cavitator 6 is higher than the productivity of the disperser 4.

The proposed technological unit scheme is linear, convenient from the point of view of the automation of the technological process. At the same time, such a scheme allows flexible management of fuel production, allowing to obtain: high calorific value (up to 6000 $\mathrm{kcal} / \mathrm{kg}$ ); low ash content (1-1.5\%); good fluidity (900-1000 cps in the temperature range of 20-70 ${ }^{\circ} \mathrm{C}$ ) and high stability (retains its structure when stored for at least 1 year and when transported by road at a distance of at least $500 \mathrm{~km}$ ).

The fuel system's stability is an indicator of the change over time in different characteristics during transportation or stationary storage and is a critical commodity characteristic.

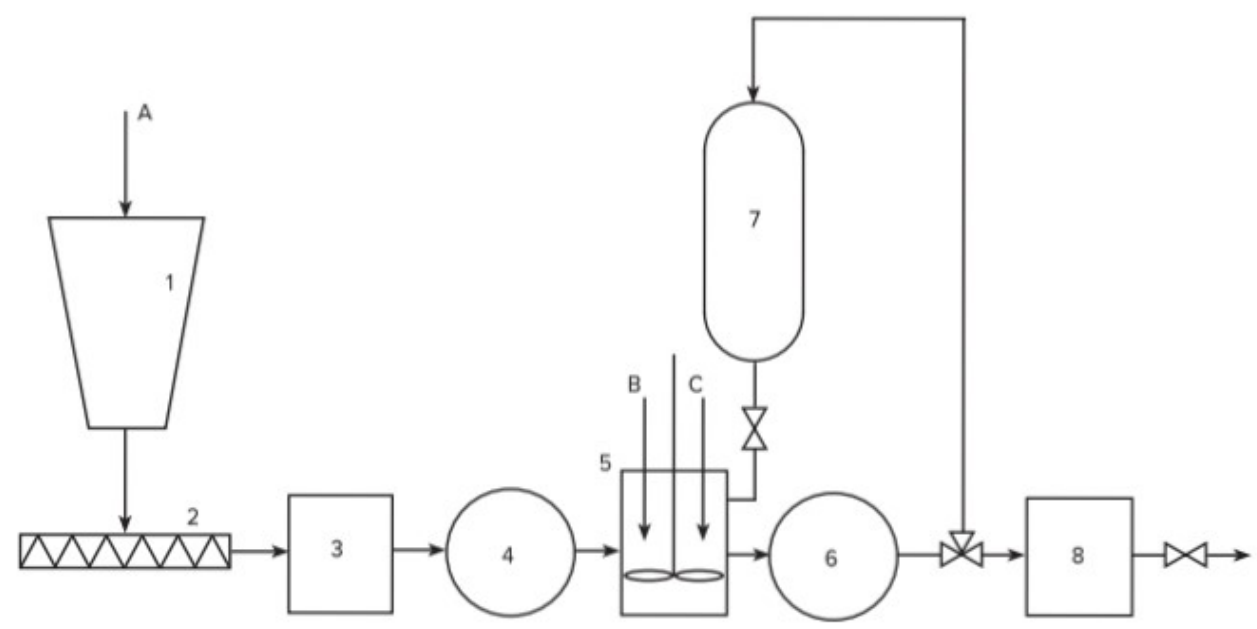

Fig. 2. Scheme of the technological line for the production of synthetic composite liquid fuel: 1 - coal bunker; 2 - feeder-dispenser; 3 - crusher; 4 - dispersant; 5 - mixer;

6 - cavitator; 7 - buffer tank; 8 - tank of finished artificial composite liquid fuel (ACLF);

A - coal; B - water; C - technological additives.

Increasing the stability of CWF can be achieved by the following methods:

- the introduction into the CWF of additives that create a "steric hindrance" for the coagulation of particles or create an electrostatic barrier between the solid phase particles;

- the formation of an ultradispersed phase in CWF (with a particle size of less than 1 micron) and a bimodal distribution of solid particles in the system;

- mechanochemical activation of both solid and liquid phases due to the sequential processing of components in disintegrators and cavitators.

From the physical chemistry of defective crystals, a solid containing an increased number of defects compared with the equilibrium one has a higher reactivity. The work of dispersion increases with a decrease in the particle size. It is explained that as the particle size decreases, their defectiveness decreases, and a transition occurs from brittle fracture to a viscous state, while a kind of equilibrium is observed: fracture - aggregation with a predominance of plastic flow. Then processing in a cavitator is a method for obtaining a substance in a finely dispersed state and generating various types of structural defects in the bulk and active states on the surface of dispersed particles to increase their reactivity. It is also interesting that under cavitation, action on the liquid phase (water) leads to a change in its physical characteristics, which persist for a long time. This is how the destruction of the carrier phase is observed as a result of cavitation action and the mechanical reactions caused by it (1-5): 


$$
\begin{gathered}
\mathrm{H}_{2} \mathrm{O} \rightarrow \mathrm{H}+\mathrm{OH} ; \\
\mathrm{OH} \rightarrow \mathrm{OH}+h y ; \\
\mathrm{OH}+\mathrm{OH} \rightarrow \mathrm{H}_{2}+\mathrm{O}_{2} ; \\
\mathrm{OH}+\mathrm{H}_{2} \mathrm{O}_{2} \rightarrow \mathrm{HO}_{2}+\mathrm{H}_{2} \mathrm{O} ; \\
\mathrm{OH}+\mathrm{H}_{2} \mathrm{O} \rightarrow \mathrm{H}_{2} \mathrm{O}+\mathrm{O}_{2} .
\end{gathered}
$$

An exciting water molecule, along with radiation and dissipation of excess energy into heat, can dissociate by reactions $(*)$. Thermolysis of water leads to the synthesis of $\mathrm{H} 2 \mathrm{O} 2$ and helps to lower the $\mathrm{pH}$. The results obtained confirm the conclusion about the cavitation mechanism of the excitation of reactions $\left(^{*}\right)$ and the achievement of metastable activated states of the fuel. The appearance of active molecules $\mathrm{H}_{2}, \mathrm{O}_{2}$, and $\mathrm{O}_{3}$ in the interfacial medium have been experimentally confirmed.

Thus, the cavitation treatment duration of a synthetic composite liquid fuel should not exceed the second period (40 min). In this case, we obtain an activated dispersed phase and an activated interdispersed medium, which contributes to the manifestation of the effect of electrostatic repulsion and a structural-mechanical barrier and stable stabilization. An increase in the reactivity of activated synthetic quasi-liquid fuel does not diminish the advantages of water-coal fuel, such as:

- reduction of toxicity in all technological operations (preparation, transport, combustion);

- explosion and fire safety in all technological operations;

- no dust.

Coal-water fuel compares favorably with traditional coal fuel oil by reducing the number of harmful substances emitted into the atmosphere during combustion, which various authors have repeatedly noted.

Ways to improve the efficiency of coal-derived motor fuel:

1. Increasing the efficiency of using emulsification of motor fuel. Improving thermal installations' efficiency and environmental cleanliness on liquid fuel is possible by using a fuel emulsion: water - fuel oil, water - diesel fuel, water - fuel oil - coal dust. Of course, water does not burn as part of a fuel emulsion, but water vapor decomposes into radicals, which catalyze oxidative reactions during fuel combustion. At present, the technical capabilities of the equipment used for the preparation of emulsions (rotary-pulsation apparatus and static-type cavitators) have been exhausted.

It is also uneconomical to use magnetostrictive ultrasound generators for dispersing emulsions and devices of a vortex layer, where dispersion occurs on ferromagnetic needles in a rotating electromagnetic layer. At the same time, the stability of the structure of the fuel emulsion remains the most important performance indicator. Considering these problematic points, the author set himself the task of focusing on the personnel of boiler houses, not on symposia. He proposed a wave disperser - a device of a fundamentally new type, the use of which makes it possible to obtain ultra-stable water-fuel emulsions. The stability of the emulsion obtained on such a device was tested on an Eppendorf centrifuge, in a critical mode, which ensures the separation of DNA from cells, which makes it possible to obtain and burn fuel based on liquid hydrocarbons in boilers without losing its quality during long-term storage.

2. Improving the quality of liquid fuel using the magnetic treatment.

It is known that in a magnetic field, hydrocarbons, which are dielectrics, are polarized. In this regard, the magnetic treatment of liquid fuel leads, with the same amount of fuel, to an improvement in the composition of exhaust gases and a decrease in fuel consumption. However, in our country, until now, magnetic technologies have not received widespread use, and the environment continues to be polluted during the operation of transport and 
boiler houses, emitting high amounts of carbon monoxide into the atmosphere. The main reason for the incomplete combustion of fuel is poor mixing with air. When injected, the fuel tends to combine into large droplets, and combustion continues for some time in the chimney, settling in the form of soot, reducing the efficiency of the МГEs. Considering also that fuels and lubricants produced in Russia contain an increased sulfur content, which leads to coking. The use of induction catalysis will eliminate such consequences and replace the actions of fuel additives that increase their octane and cyan number and drugs that thin fuel during the winter period of operation.

\section{References}

1. I. Kapkaev, I. Dobrovolsky, D. Sorokin, E3S Web Conf. 12016, 175 (2020) https://doi.org/10.1051/e3sconf/202017512016

2. M. Shpirt, E. Gorlov, A. Shumovskii, Solid Fuel Chemistry 54(1) (2020) DOI: 10.3103/S0361521920010073

3. A. Staroń, Z. Kowalski, P. Staroń, M. Banach, Fuel Processing Technology 152 (2016) DOI: 10.1016/j.fuproc.2016.07.007

4. S. Hu, L. Liu, X. Yang, J. Li, B. Zhou, C. Wu, L. Weng, K. Liu, RSC Advances 9(56) (2020) DOI: 10.1039/c9ra04391h

5. H. Singh, S. Kumar, S. Mohapatra, International Journal of Coal Preparation and Utilization (2018) DOI: 10.1080/19392699.2018.1461624

6. K. Kojobaev, K. Tazhibaev, D. Tazhibaev, K. Duisheev, Gornyi Zhurnal 8, (2016) DOI: $10.17580 /$ gzh.2016.08.12

7. M. Shpirt, G. Gorlov, A. Shumovskii, Solid Fuel Chemistry 54(1) (2020) DOI: 10.3103/S0361521920010073.

8. N. Harihastuti, R. Yuliasni, E3S Web of Conferences 01012, 73 (2018) DOI: 10.1051/e3sconf/20187301012.

9. C. Zhang, R. Gao, K.-W. Jun, H.-G. Park, G. Guan, Journal of CO2 Utilization 34 (2019) DOI: 10.1016/j.jcou.2019.07.005

10. K. Jąderko-Skubis, International Journal of Sustainable Engineering (2020) DOI: 10.1080/19397038.2020.1836063

11. R. Tabakaev, I. Shanenkov, A. Kazakov, A. Zavorin, Journal of Analytical and Applied Pyrolysis 124 (2017) DOI: 10.1016/j.jaap.2017.02.016

12. E.B. Shlikhter, A.V. Khor'kov, Yu.M. Zhorov, Solid Fuel Chemistry 14(6), 40-46 (1980) 